\title{
IGF gene polymorphisms and breast cancer in African-American and Hispanic women
}

\author{
MARIANNA SARKISSYAN ${ }^{1}$, DHRUVA KUMAR MISHRA ${ }^{1}$, YANYUAN WU ${ }^{1,2}$, \\ XIYING SHANG $^{1}$, SUREN SARKISSYAN ${ }^{1}$ and JAYDUTT V. VADGAMA ${ }^{1,2}$ \\ ${ }^{1}$ Division of Cancer Research and Training, Center to Eliminate Cancer Health Disparities, \\ Department of Internal Medicine, Charles Drew University of Medicine and Science, Los Angeles, CA 90059; \\ ${ }^{2}$ Jonsson Comprehensive Cancer Center, University of California at Los Angeles, Los Angeles, CA 90059, USA
}

Received January 18, 2011; Accepted March 11, 2011

DOI: $10.3892 /$ ijo.2011.990

\begin{abstract}
Previous studies from our group and others have shown that increased circulatory levels of the ligand insulinlike growth factor 1 (IGF-1) and decreased levels of the predominant IGF-1 binding protein 3 (IGFBP-3) are associated with an increased incidence of breast cancer and poor outcome. Some studies suggest that, in addition to the influence of environmental factors on the levels of IGF-1 and IGFBP-3, alterations in their gene polymorphisms may play a significant role in the risk of cancer. In this study, we investigated the association between gene polymorphisms along the IGF axis and breast cancer, including the IGF-1 (CA) dinucleotide repeat, IGFBP-3 A-202C single nucleotide polymorphism, and the 2-bp deletion and (AGG)n repeat polymorphisms in the IGF type 1 receptor (IGF-IR). A total of 654 subjects, including both African-American and Hispanic/Latino subjects, were screened for various gene polymorphisms. IGF gene polymorphism genotyping was performed by PCR-GeneScan and PCR-RFLP methods. Our results demonstrated a significant association between the non-19/non-19 IGF-1 (CA)n polymorphism and breast cancer $(\mathrm{OR}=1.75 ; 95 \% \mathrm{CI}=1.07-2.88 ; \mathrm{P}=0.027)$. Furthermore, absence
\end{abstract}

Correspondence to: Dr Jay V. Vadgama, Division of Cancer Research and Training, Charles Drew University of Medicine and Science, 1731 East 120th Street, Los Angeles, CA 90059, USA

E-mail: javadgama@cdrewu.edu; jvadgama@ucla.edu

Abbreviations: IGF-1, insulin-like growth factor 1; IGFBP-3, insulin-like growth factor binding protein 3; IGF-1R, insulin-like growth factor 1 receptor; OR, odds ratio; CRC, colorectal cancer; HNPCC, hereditary non-polyposis colon cancer; CI, confidence interval; BMI, body mass index; PCR, polymerase chain reaction; SNP, single nucleotide polymorphism; RFLP, restriction fragment length polymorphism

Key words: insulin-like growth factor 1, insulin-like growth factor binding protein 3 , insulin-like-growth factor 1 receptor, breast cancer, genetic polymorphism, African Americans, Hispanic Americans of the wild-type-19 allele and alleles $<(\mathrm{CA}) 19$ were strongly associated with breast cancer $(\mathrm{OR}=1.82$; $95 \% \mathrm{CI}=1.20-2.77$; $\mathrm{P}=0.005$ and $\mathrm{OR}=1.70 ; 95 \% \mathrm{CI}=1.19-2.43 ; \mathrm{P}=0.003$, respectively). The association of the non-19/non-19 polymorphism with breast cancer was also more significant in premenopausal women $(\mathrm{P}=0.04)$. We did not find any significant association of the IGFBP-3 polymorphism with breast cancer. In the case of IGF-1R polymorphisms, the only significant trend was in the (AGG)5 allele; however, the frequency of this allele was very rare. In summary, our study demonstrated a significant association of IGF-1 polymorphisms and breast cancer. Future studies are necessary to understand the mechanistic value of these polymorphisms in breast cancer risk.

\section{Introduction}

Insulin-like growth factor-1 (IGF-1) is a critical growth factor that plays diverse biological roles. Most IGF-1 is found in circulation with the liver being the major source, but in vitro studies have clearly shown that almost all tissues express IGF-1 and the IGF-1 receptor (IGF-1R) (1). The bioavailability of IGF-1 in circulation is regulated by IGF binding proteins (IGFBPs) with the most highly associated IGF-1 binding protein being IGFBP-3. The IGFBPs enact a role in IGF-1 action by increasing the half-life of IGF-1 and sequestering IGF-1 from binding IGF-1R as a free ligand $(1,2)$. Due to its important role in cellular proliferation and apoptosis, IGF-1 is an important mediator in oncogenic processes $(3,4)$.

Multiple studies have shown an association between high levels of IGF-1 and elevated risk of breast cancer (5-13). In addition, IGF-1 and IGFBP-3 circulatory levels have been associated with progression, recurrence and survival of breast cancer $(5,6)$. Although the levels of IGF-1 may be affected by environmental and lifestyle factors, there is evidence that a significant amount of IGF-1 expression may be influenced by genetic variables (14). Studies have suggested that one such genetic variable may be a (CA)n dinucleotide repeat polymorphism 969-base pairs upstream from the transcription start site which may affect transcriptional levels of IGF-1 (15). Polymorphic simple sequence repeats (SSRs), including (CA)n repeats, have been extensively studied and implicated in the etiology of many diseases, exerting regulatory roles 
over transcription often in an inverse manner (16). Thus, the (CA)n promoter polymorphism in IGF-1 may modulate tumorigenesis via increased serum levels (17-20). The repeats of the CA dinucleotide sequence have been reported to range from 13 to 25 times with the 19 repeat being the most common (18). In the IGFBP-3 gene, the -202 locus has a single nucleotide polymorphism adenine to cytosine $(A>C)$ that can produce three genotypes; AA (wild-type), AC (heterozygous) and CC (mutant homozygous). The IGFBP-3 polymorphism is implicated in breast cancer since it may affect the transcriptional levels of IGFBP-3 and consequently regulate IGF-1 availability and function. Studies have found that the serum levels of IGFBP-3 are inversely associated with the polymorphic status $(19,20)$. The IGF-1 receptor is a well studied tyrosine receptor kinase which stimulates both the pro-growth MAPK signal transduction pathways and the anti-apoptotic PI3K/Akt pathway (1). Furthermore, IGF-1R has been identified as being an important component in tumor transformation and promotion of tumor growth via interactions with oncogenes and tumor-suppressor genes such as p53 $(21,22)$. Higher levels of IGF-1R have been associated with various tumor types $(23,24)$ where the increased levels of the receptor could presumably provide increased IGF-1-mediated signaling. Polymorphisms that affect the non-coding regulatory regions of genes, such as untranslated regions (UTRs) which contribute to the stability of mRNA, may therefore contribute to tumorigenesis and progression by increasing the half-life of the mRNA transcript resulting in increased protein translation. There are two gene polymorphisms of interest in the non-coding regions of IGF-1R which were investigated in this study. One polymorphism is a microsatellite trinucleotide repeat of $A G G$, which can vary from being repeated five to nine times, with seven repeats (AGG)7 considered the most common and 'wild-type'. The second polymorphism is a 2-base pair deletion ( $2 \mathrm{bp}$-del) in the 3 'UTR region. Thus, our current study aimed to assess the potential association between genetic polymorphisms in the IGF-1, IGFBP-3 and IGF-1R genes, and breast cancer.

\section{Materials and methods}

Subject selection. The women from this study were recruited from South Los Angeles County, CA. Women visiting the Mammography Clinic or the Hematology/Oncology Clinic at the Martin Luther King Ambulatory Care Center (MACC, formerly known as King-Drew Medical Center) between 1995 and 2005 were offered the option to participate in an ongoing breast cancer study conducted in the Division of Cancer Research and Training at Charles Drew University of Medicine and Science and MACC. Recruitment was conducted by bilingual interviewers who obtained informed and signed consent from the subjects approved by the Internal Review Board at Charles Drew University. Upon consent, participating women donated a 5- to 7-ml blood sample that was separated into plasma, serum, red blood cells, and buffy coat components and stored at $-80^{\circ} \mathrm{C}$ until experimental use.

The women included in this study were subjects from our existing database in the Division of Cancer Research and Training at Charles Drew University. The majority of the subjects were self-reported as African American or Hispanic/
Latino, and only these two ethnic groups were included in the study. The ethnic composition of the study reflected the patient population at the MACC Medical Center in South-Central Los Angeles which is comprised primarily of underserved African-American and Hispanic/Latino populations. The 5\% of subjects who were self-reported as Caucasian and Asian were not included in the study since it was not possible to perform meaningful analysis with the small number of subjects from these ethnicities. Personal history and medical information were abstracted from the medical charts of the subjects.

Subject category definitions. Women categorized as 'cases' or 'women with breast cancer' were women for whom breast cancer status was determined from biopsy/pathologyconfirmed neoplasm of the breast. Only subjects who had clear documentation of biopsy/pathology information were included in the study. The women categorized as 'controls' or 'women without breast cancer' included normal subjects who came to the Mammography Clinic for routine mammogram and had a normal mammography result; and women who had radiology/pathology-confirmed benign breast disease. Only subjects who had documentation of either disease-free mammography or biopsy with benign results were included in the study. Only African-American and Hispanic subjects older than 30 years of age were included in the study in order to closer match controls with the cancer patients in the study who were usually older. An additional criterion for inclusion into the study was the availability of a blood sample from the subject and whether the quality of DNA extracted from the buffy coat of the donated blood samples was amplifiable for polymorphic analysis. We excluded women for whom breast cancer was not the primary cancer; or their breast cancer was not the first cancer in their lifetime; or subjects who were undergoing current evaluation for cancer.

Clinicopathological definitions. Clinicopathological tumor characteristics (stage, hormone receptor status) for breast cancer patient information were extracted from the patient medical records. Thus, availability of complete medical records for each patient was also an inclusion requirement. For the breast cancer patients, the histological classification of the breast tumor was directly extracted from the patient's surgical pathology report in the medical chart. The TNM staging was defined according to AJCC definitions. The lymph node status was defined as negative when $\mathrm{N}$ was $\mathrm{N} 0$, positive when $\mathrm{N}$ was $\mathrm{N} 1, \mathrm{~N} 2, \mathrm{~N} 3$. Tumor size was defined according to the AJCC definitions. The receptor status was defined as $\mathrm{ER}^{+} / \mathrm{PR}^{+} / \mathrm{HER} 2^{-}, \mathrm{ER}^{+} / \mathrm{PR}^{+} / \mathrm{HER}^{+}, \mathrm{ER}^{-} / \mathrm{PR}^{-} / \mathrm{HER}^{+}$, and triple-negative (ER $\left./ \mathrm{PR}^{-} / \mathrm{HER}^{-}\right)$. ER/PR status was considered positive when $>5 \%$ of the tumor cell nuclei were immunoreactive, or negative if otherwise. HER2 status was considered positive when HER 2 was $3+$, negative when HER2 was $0,1+$, and $2+$ as determined by IHC.

Genotyping of the IGF-1 polymorphism. Genomic DNA of the subjects was extracted from buffy coat using a DNA extraction kit (Gentra Systems, MN). The PCR-GeneScan method was used to genotype the dinucleotide repeats in the promoter region of the IGF-1 gene. PCR amplification was conducted using the following primers: 
forward, 5'-ACCACTCTGGGAGAAGGGTA-3'; reverse, 5'-GCTAGCCAGCTGGTGTTATT-3' (Retrogen Inc., USA). The forward primer was Fam-labeled for fluorescence detection. The PCR mixture had a total volume of $10 \mu \mathrm{l}$ and consisted of $100 \mathrm{ng}$ of genomic DNA, 6 pmol of each primer, $0.2 \mu \mathrm{mol} / 1 \mathrm{dNTPs}, 2.0 \mathrm{mmol} / 1 \mathrm{MgCl}_{2}, 1.5 \mathrm{U}$ Taq polymerase (Qiagen, USA) and $1 \mu \mathrm{l} 10 \mathrm{X}$ PCR buffer (pH 8.0). The cycling conditions began with an initial denaturation at $94^{\circ} \mathrm{C}$ for 5 min which was then followed by 35 cycles at $94^{\circ} \mathrm{C}$ for $30 \mathrm{sec}, 61^{\circ} \mathrm{C}$ for $30 \mathrm{sec}, 72^{\circ} \mathrm{C}$ for $30 \mathrm{sec}$ and a final extension for $7 \mathrm{~min}$ at $72^{\circ} \mathrm{C}$. PCR products were sent to UCLA Sequencing and Genotyping Core for GeneScan. Of the PCR products, $3 \mu \mathrm{l}$ of each sample was mixed with $0.3 \mu 1$ of LIZ500 and $10 \mu \mathrm{l}$ of HiDi formamide. Samples were then denatured for $5 \mathrm{~min}$ at $95^{\circ} \mathrm{C}$ and cooled on ice before loading on ABI3730XL. Analysis was carried out with GeneMapper (version 4.0) software. We obtained the fragment size, height, and area of peaks of each sample and calculated the number of dinucleotide CA repeats. Furthermore, we confirmed GeneScan results by sequencing random samples in order to ascertain the accuracy of the resulting number of repeats calculated in this manner.

Genotyping of the IGFBP-3 polymorphism. The IGFBP-3 PCR amplification was performed using the forward primers 5'-CCACGAGGTACACACGAATG-3' and reverse primers 5'-AGCCGCAGTGCTCGCATCTGG-3'. The PCR mixture had a total volume of $25 \mu \mathrm{l}$ and consisted of $100 \mathrm{ng}$ genomic DNA, $1 \mathrm{pmol}$ of primers, $1.5 \mathrm{mmol} / 1 \mathrm{MgCl}_{2}, 0.1 \mathrm{mmol} / 1$ of each dNTPs, $2 \mathrm{U}$ Taq DNA polymerase (Qiagen), $5 \mu 1$ Q-solution and $2.5 \mu 1$ 10X PCR buffer. The reaction was carried out using a 10 -min denaturation at $94^{\circ} \mathrm{C}$, followed by 36 cycles of $40 \mathrm{sec}$ at $94^{\circ} \mathrm{C}, 40 \mathrm{sec}$ at $60.4^{\circ} \mathrm{C}, 40 \mathrm{sec}$ at $72^{\circ} \mathrm{C}$ and a final extension of $7 \mathrm{~min}$ at $72^{\circ} \mathrm{C}$. The IGFBP-3 A-202C polymorphism was identified using restriction fragment length polymorphism (RFLP) analysis. From the PCR product, $8 \mu \mathrm{l}$ was digested with $5 \mathrm{U}$ of Alw21I (Fermentas, Canada) in a total volume of $15 \mu \mathrm{l}$ for $16-18 \mathrm{~h}$ at $37^{\circ} \mathrm{C}$. Digested products were visualized on a $1.5 \%$ agarose gel stained with ethidium bromide. The amplified IGFBP-3 PCR product contains three Alw21I sites, one of which is eliminated when there is a $\mathrm{C}$ at -202. Thus, the AA genotype results in 242- and 162-bp products, AC genotype results in 280-, 242- and 162-bp products, and the CC genotype results in 280- and 162-bp products.

Genotyping of the IGF-1R polymorphisms. Identification of (AGG)n and 2 bp-del polymorphisms in IGF-1R was performed using the PCR-GeneScan method as described by Chen et al (25). The PCR primers used to amplify the region of interest for the AGG repeat were the following: forward (Fam-labeled), 5'-GCTGAGGGAGGAGGCGGC-3' and reverse, 5'-GGCGAGGGGCAGAAACGC-3'; nested forward, 5'-CCTGGATTTGGGAAGGAGCTCG-3' and nested reverse, 5'-GAAGTCCGGGTCACAGGCGA-3'. The primers used to amplify the region of interest for the 2-bp deletion were the following: forward, 5'-CTCCTCTCTGCTTCATAACG-3' and reverse (TET-labeled), 5'-TCCGGACACGAGGAATCAGC-3'. The cycling conditions were according to the conditions used by Chen et al (25). PCR products were sent to UCLA Sequencing and Genotyping Core for GeneScan as described above. We received the fragment size, height and area of the peaks of each sample and calculated the number of trinucleotide repeats and identified the presence/absence of the 2-base pair deletion.

Analysis. The parameters considered included age, ethnicity, breast cancer status, IGF-1, IGFBP-3 and IGF-1R polymorphic genotypes. IGF-1 genotypes were compared according to i) 19 CA repeat status in both alleles (19/19, 19/non-19 and non-19/ non-19) or ii) CA repeats in one allele. Based on previous studies of the IGF-1 (CA)n reflective of the postulated transcriptional consequences exerted by the length of the repeats $(15,17,26-37)$, the CA repeats in both alleles less or more than $19 \mathrm{CA}$ repeats were also compared to those with equal 19 CA repeats $[<(C A) 19,=(C A) 19,>(C A) 19]$. When IGF-1 $(C A) n$ repeats in one allele were used for comparison, the CA repeat information from each subject was used twice [i.e. a subject with a IGF-1 (CA)n genotype of 19/20, would be represented in both the IGF-1 (CA)19 percentage and the IGF-1 (CA)20 percentage]. The purpose of the Group 1 comparison was to assess the effect of the wild-type vs. non-wild-type genotype in the association of this polymorphism with breast cancer. The addition of the Group 2 comparison was to assess whether the proposed functional relevance of the polymorphic dinucleotide repeat length was significant in the context of cancer. As mentioned in the introduction, the length of the repeats may be inversely associated with transcriptional levels of the gene; since levels of IGF-1 have been associated with breast cancer and outcomes, this was an important comparison to consider. Group 3 assessed the presence of the wild-type allele compared to the absence of the wild-type allele. The IGF-1R 2 bp-del polymorphism was grouped by the presence of the wild-type allele (non-del) compared to the presence of the polymorphic $2 \mathrm{bp-del}$. The variables in this resulting group were non-del/non-del, non-del/2 bp-del and $2 \mathrm{bp}-\mathrm{del} / 2 \mathrm{bp}-\mathrm{del}$. The (AGG) polymorphism in IGF-1R was categorized in two ways. In the first, called Group 1, the polymorphism grouping was based on the presence or absence of the wild-type (AGG)7 genotype compared to the non-wild-type genotypes; (AGG)7/(AGG)7, (AGG)7/ (AGG)non, (AGG)non/(AGG)non. The second method, as in Group 2, was the actual number of repeats; (AGG)n/(AGG)n. These two grouping methods were chosen such that both the overall affect of the presence or the absence of the wild-type allele could be assessed, as well as the affect of the specific polymorphic genotypes.

Statistical analysis was performed using SPSS software (SPSS, Inc., Chicago, IL). Characteristics of the subjects in the different groups were compared by the $\chi^{2}$ test. The distributions of CA repeats in both alleles, and the variation of 19 CA repeats of IGF-1 were compared between breast cancer and non-cancer using the $\chi^{2}$ test. Similarly, the differences in IGFBP-3 genotypes in breast cancer and non-breast cancer were compared by $\chi^{2}$ test. The distribution of both the IGF-1R polymorphisms, in all grouping methods, among breast cancer vs. non-cancer subjects also used the $\chi^{2}$ test. The association of breast cancer with IGF-1, IGFBP-3, and IGF-1R genotypes were determined by logistic regression with univariate and multivariate analysis. Furthermore, the association between the IGF genotypes and the clinicopathological features were 
Table I. Characteristics of the study population.

\begin{tabular}{|c|c|c|c|}
\hline & $\begin{array}{c}\text { Cases } \\
\text { no. }(\%)\end{array}$ & $\begin{array}{c}\text { Controls } \\
\text { no. }(\%)\end{array}$ & P-value \\
\hline Total subjects in the study & $268(41)$ & $386(59)$ & \\
\hline \multicolumn{4}{|l|}{ Ethnicity } \\
\hline African American & $138(51)$ & $85(22)$ & $<0.01$ \\
\hline Hispanic/Latino & $130(49)$ & $301(78)$ & \\
\hline \multicolumn{4}{|l|}{ Histology $(n=227)$} \\
\hline Infiltrating ductal carcinoma & $170(75)$ & - & - \\
\hline Infiltrating lobular carcinoma & $41(18)$ & - & \\
\hline Infiltrating adenocarcinoma & $9(4)$ & - & \\
\hline Ductal carcinoma in situ & $2(1)$ & - & \\
\hline Lobular carcinoma in situ & $5(2)$ & - & \\
\hline \multicolumn{4}{|l|}{ Stage $(n=218)$} \\
\hline 0 -II & $146(67)$ & - & - \\
\hline III-IV & $72(33)$ & - & - \\
\hline \multicolumn{4}{|l|}{ Lymph node $(\mathrm{n}=225)$} \\
\hline Negative & $94(42)$ & - & - \\
\hline Positive & $131(58)$ & - & - \\
\hline \multicolumn{4}{|l|}{ Tumor size $(\mathrm{n}=221)$} \\
\hline T0/Tis/T1 & $54(24)$ & - & - \\
\hline $\mathrm{T} 2$ & $102(46)$ & - & \\
\hline $\mathrm{T} 3 / \mathrm{T} 4$ & $65(30)$ & - & \\
\hline \multicolumn{4}{|l|}{ ER/PR status $(n=226)$} \\
\hline ER/PR positive & $127(56)$ & - & - \\
\hline ER/PR negative & $99(44)$ & - & \\
\hline \multicolumn{4}{|l|}{ HER2 status $(\mathrm{n}=195)$} \\
\hline HER2 negative & $45(23)$ & - & - \\
\hline HER2 positive & $150(77)$ & - & \\
\hline \multicolumn{4}{|l|}{ Subtype $(n=194)$} \\
\hline Luminal A & $85(44)$ & - & - \\
\hline Luminal B & $16(8)$ & - & \\
\hline ER/PR-/HER2 ${ }^{+}$ & $28(14)$ & - & \\
\hline Triple-negative & $65(34)$ & - & \\
\hline
\end{tabular}

Age criterion for subject selection was $>30$ years.

assessed by the $\chi^{2}$ test. All multivariate analyses performed were adjusted for age and BMI category $(<18.5$ underweight, 18.5-24.9 normal weight, 25-29.9 overweight, $>30$ obese). Only the two-sided P-value $<0.05$ was considered statistically significant.

\section{Results}

Characteristics of the study population. A total of 654 subjects were assessed in this study, including 268 breast cancer patients and 386 women with no breast cancer. A description of the menopausal status and ethnicity of the subjects is shown in Table I. When assessing the self-reported ethnic description of the study subjects, there were a similar number of cases from both ethnicities (138 for African Americans, 130 for Latinos). However, there was a significant difference $(\mathrm{P}<0.01)$ in the distribution of controls, with more Latino women in the study than African-American women. The clinicopathological features of the breast cancer patients are also described in Table I. The majority of cancer patients in this study had a breast tumor histology described as infiltrating ductal carcinoma (75\%), followed by infiltrating lobular carcinomas (18\%), with the remainder having infiltrating adenocarcinoma, ductal carcinoma in situ, and lobular carcinoma in situ.

Distribution of the IGF-1 (CA)n genotype in the study population. The IGF-1 genotype distributions in the total cohort and in subcategories based on menopausal status are shown in Table II. In the IGF-1 genotype distribution, alleles characterized by the number of $\mathrm{CA}$ repeats ranged from (CA)14 to (CA)25. The (CA)19 allele was the most common across all categories and subdivisions (>47\%). Some general trends in the different distribution of alleles between the cases and controls were observed. When grouping the subjects by the polymorphic genotypes (19/19, 19/non-19, non-19/non-19) as in Group 1, there was a significant difference between the cases and controls in the total cohort $(\mathrm{P}=0.03)$. The non-19/ non-19 genotype was present in $31.7 \%$ of the cases compared to only $20.3 \%$ of the controls. Furthermore, when assessing the difference in the genotype distribution by menopausal status, a statistically significant association was observed for the non-19/non-19 genotype in premenopausal women with breast cancer. The non-19/non-19 genotype was present in $32.1 \%$ of the premenopausal cases and only $18.9 \%$ of the premenopausal controls $(\mathrm{P}=0.04)$. Stratification according to the specific length of the genotype also revealed that the $<(\mathrm{CA}) 19$ alleles were more frequently found in the cases than in the controls. This trend was observed when grouping the frequency of alleles by $<(\mathrm{CA}) 19,=(\mathrm{CA}) 19$ and $>(\mathrm{CA}) 19$ as in Group 2. The percentage of cases with the $<$ (CA) 19 allele was $21 \%$ compared to $14 \%$ of the controls. When assessing the 'presence of the 19 allele' vs. the 'absence of the 19 allele' in the study subjects as in Group 3, there was a statistically significant association of the latter genotypes with breast cancer in the total cohort $(\mathrm{P}<0.01)$ as well as in the premenopausal cases $(\mathrm{P}=0.01)$. In summary, the distribution of the (CA)n alleles revealed that there was an association of the $<(\mathrm{CA}) 19$ allele as well as the non-(CA)n alleles with breast cancer, particularly in premenopausal women.

Distribution of the IGFBP-3 genotype in the study population. The distribution of the IGFBP-3 genotypes is shown in Table III. In the total cohort, the most common genotype was the doubly polymorphic CC (present in $42.4-46.4 \%$ of the study subjects) and the least common genotype was the wild-type AA genotype (present in 13.8-18.6\% of the study subjects). There were no statistically significant trends in the distribution of the IGFBP-3 polymorphic genotype between the cases and the controls in any of the categories.

Distribution of the IGF-1R genotype in the study population. The distribution of the IGF-1R polymorphisms is shown in Table IV. The distribution of the IGF-1R 2-base pair deletion 
Table II. Distribution of the IGF-1 (CA)n genotype in the study population.

\begin{tabular}{|c|c|c|c|c|c|c|}
\hline \multirow[b]{2}{*}{$\begin{array}{l}\text { Total subjects } \\
(\mathrm{n}=475)\end{array}$} & \multicolumn{2}{|c|}{ Total } & \multicolumn{2}{|c|}{ Premenopausal } & \multicolumn{2}{|c|}{ Postmenopausal } \\
\hline & $\begin{array}{c}\text { Case } \\
(\mathrm{n}=199) \\
(\%)\end{array}$ & $\begin{array}{c}\text { Control } \\
(\mathrm{n}=276) \\
(\%)\end{array}$ & $\begin{array}{c}\text { Case } \\
(\mathrm{n}=106) \\
(\%)\end{array}$ & $\begin{array}{c}\text { Control } \\
(n=164) \\
(\%)\end{array}$ & $\begin{array}{c}\text { Case } \\
(\mathrm{n}=93) \\
(\%)\end{array}$ & $\begin{array}{c}\text { Control } \\
(\mathrm{n}=112) \\
(\%)\end{array}$ \\
\hline \multicolumn{7}{|c|}{ IGF-1 (CA)n genotype } \\
\hline$(\mathrm{CA}) 14$ & 0.3 & - & - & - & 0.5 & - \\
\hline$(\mathrm{CA}) 15$ & 0.5 & 0.4 & 0.9 & 0.6 & 0.0 & - \\
\hline$(\mathrm{CA}) 16$ & 2.0 & 2.4 & 1.9 & 2.7 & 2.2 & 1.8 \\
\hline (CA) 17 & 4.3 & 1.6 & 4.7 & 2.1 & 3.8 & 0.9 \\
\hline$(\mathrm{CA}) 18$ & 14.4 & 10.2 & 13.7 & 9.1 & 15.1 & 11.6 \\
\hline$(\mathrm{CA}) 19$ & 48.0 & 55.3 & 47.9 & 57.0 & 47.8 & 52.2 \\
\hline$(\mathrm{CA}) 20$ & 14.6 & 11.8 & 15.2 & 9.5 & 14.0 & 15.2 \\
\hline$(\mathrm{CA}) 21$ & 14.1 & 17.1 & 15.2 & 16.5 & 12.9 & 17.9 \\
\hline$(\mathrm{CA}) 22$ & 1.5 & 1.1 & 0.5 & 1.5 & 2.7 & 0.4 \\
\hline$(\mathrm{CA}) 23$ & 0.3 & 0.4 & - & 0.6 & 0.5 & - \\
\hline (CA)24 & 0.3 & - & - & - & 0.5 & - \\
\hline (CA)25 & - & 0.2 & - & 0.3 & 0.0 & - \\
\hline Range (CA)n & $14-24$ & $15-25$ & $15-22$ & $15-25$ & $14-24$ & $16-22$ \\
\hline \multicolumn{7}{|c|}{ IGF-1 (CA)n genotype groups } \\
\hline \multicolumn{7}{|l|}{ Group $1^{\mathrm{a}}$} \\
\hline $19 / 19$ & 27.1 & 30.4 & 27.4 & 32.9 & 26.9 & 26.8 \\
\hline 19/non-19 & 41.2 & 49.3 & 40.6 & 48.2 & 41.9 & 50.9 \\
\hline Non-19/non-19 & 31.7 & 20.3 & 32.1 & 18.9 & 31.2 & 22.3 \\
\hline P-value & \multicolumn{2}{|c|}{0.03} & \multicolumn{2}{|c|}{0.04} & \multicolumn{2}{|c|}{0.39} \\
\hline \multicolumn{7}{|l|}{ Group 2} \\
\hline$<(\mathrm{CA}) 19$ & 21.4 & 14.5 & 21.5 & 14.6 & 21.5 & 14.3 \\
\hline$=(\mathrm{CA}) 19$ & 47.9 & 55.1 & 47.8 & 57.0 & 47.8 & 52.2 \\
\hline$>(\mathrm{CA}) 19$ & 30.7 & 30.4 & 30.7 & 28.4 & 30.6 & 33.5 \\
\hline P-value & \multicolumn{2}{|c|}{0.19} & \multicolumn{2}{|c|}{0.13} & \multicolumn{2}{|c|}{0.86} \\
\hline \multicolumn{7}{|l|}{ Group $3^{\mathrm{b}}$} \\
\hline 19 allele present & 68.3 & 79.7 & 67.9 & 81.1 & 67.9 & 77.7 \\
\hline 19 allele absent & 31.7 & 20.3 & 32.1 & 18.9 & 32.1 & 22.3 \\
\hline P-value & \multicolumn{2}{|c|}{$<0.01$} & \multicolumn{2}{|c|}{0.01} & \multicolumn{2}{|c|}{0.10} \\
\hline
\end{tabular}

${ }^{\mathrm{a}}(\mathrm{CA}) \mathrm{n}=19$ repeats is the wild-type (non-polymorphic genotype). All other repeats $(\mathrm{CA}) \mathrm{n}<19$ or $(\mathrm{CA}) \mathrm{n}>19$ are considered non-19. ${ }^{\mathrm{b}}$ The ' 19 allele present' is either the $19 / 19$ or 19/non-19 genotype. The '19 allele absent' is the non-19/non-19 genotype.

Table III. Distribution of the IGFBP-3 genotype in the study population.

\begin{tabular}{|c|c|c|c|c|c|c|}
\hline \multirow[b]{2}{*}{$\begin{array}{l}\text { Total subjects } \\
(n=418)\end{array}$} & \multicolumn{2}{|c|}{ Total } & \multicolumn{2}{|c|}{ Premenopausal } & \multicolumn{2}{|c|}{ Postmenopausal } \\
\hline & $\begin{array}{c}\text { Case } \\
(\mathrm{n}=172) \\
(\%)\end{array}$ & $\begin{array}{c}\text { Control } \\
(\mathrm{n}=246) \\
(\%)\end{array}$ & $\begin{array}{c}\text { Case } \\
(\mathrm{n}=103) \\
(\%)\end{array}$ & $\begin{array}{c}\text { Control } \\
(\mathrm{n}=147) \\
(\%)\end{array}$ & $\begin{array}{c}\text { Case } \\
(\mathrm{n}=69) \\
(\%)\end{array}$ & $\begin{array}{c}\text { Control } \\
(\mathrm{n}=99) \\
(\%)\end{array}$ \\
\hline \multicolumn{7}{|c|}{ IGFBP-3 genotype ${ }^{a}$} \\
\hline AA & 18.6 & 13.8 & 19.4 & 13.6 & 17.4 & 14.1 \\
\hline $\mathrm{AC}$ & 39.0 & 39.8 & 41.7 & 40.1 & 34.8 & 39.4 \\
\hline $\mathrm{CC}$ & 42.4 & 46.4 & 38.9 & 46.3 & 47.8 & 46.5 \\
\hline P-value & \multicolumn{2}{|c|}{0.227} & \multicolumn{2}{|c|}{0.153} & \multicolumn{2}{|c|}{0.868} \\
\hline
\end{tabular}

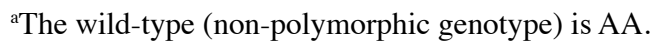


Table IV. Distribution of the IGF-1R genotype in the study population.

\begin{tabular}{|c|c|c|c|c|c|c|}
\hline \multirow[b]{2}{*}{$\begin{array}{l}\text { Total subjects } \\
(\mathrm{n}=496)\end{array}$} & \multicolumn{2}{|c|}{ Total } & \multicolumn{2}{|c|}{ Premenopausal } & \multicolumn{2}{|c|}{ Postmenopausal } \\
\hline & $\begin{array}{c}\text { Case } \\
(\mathrm{n}=222) \\
(\%)\end{array}$ & $\begin{array}{c}\text { Control } \\
(\mathrm{n}=274) \\
(\%)\end{array}$ & $\begin{array}{c}\text { Case } \\
(\mathrm{n}=106) \\
(\%)\end{array}$ & $\begin{array}{c}\text { Control } \\
(\mathrm{n}=166) \\
(\%)\end{array}$ & $\begin{array}{c}\text { Case } \\
(\mathrm{n}=116) \\
(\%)\end{array}$ & $\begin{array}{c}\text { Control } \\
(\mathrm{n}=108) \\
(\%)\end{array}$ \\
\hline \multicolumn{7}{|l|}{ IGF-IR 2-bp deletion ${ }^{\mathrm{a}}$} \\
\hline Non-del/non-del & 64.9 & 64.2 & 65.1 & 66.9 & 64.7 & 60.2 \\
\hline Non-del/2 bp-del & 27.4 & 30.7 & 28.3 & 28.9 & 26.7 & 33.3 \\
\hline $2 \mathrm{bp}-\mathrm{del} / 2 \mathrm{bp}-\mathrm{del}$ & 7.7 & 5.1 & 6.6 & 4.2 & 8.6 & 6.5 \\
\hline P-value & \multicolumn{2}{|c|}{0.73} & \multicolumn{2}{|c|}{0.57} & \multicolumn{2}{|r|}{0.78} \\
\hline \multicolumn{7}{|l|}{ IGF-IR (AGG)n ${ }^{b}$} \\
\hline (AGG)5 & 3.0 & 0.9 & 3.1 & 1.3 & 2.9 & 0.5 \\
\hline$(\mathrm{AGG}) 6$ & 26.6 & 31.7 & 29.7 & 30.4 & 23.6 & 33.6 \\
\hline$(\mathrm{AGG}) 7$ & 69.8 & 67.4 & 66.7 & 68.3 & 72.7 & 65.9 \\
\hline$(\mathrm{AGG}) 8$ & 0.4 & - & 0.5 & - & 0.4 & - \\
\hline$(\mathrm{AGG}) 9$ & 0.2 & - & - & - & 0.4 & - \\
\hline Range (AGG)n & $(\mathrm{AGG}) 5-9$ & $(\mathrm{AGG}) 5-7$ & (AGG) 5-8 & $(\mathrm{AGG}) 5-7$ & $(A G G) 5-9$ & $(\mathrm{AGG}) 5-7$ \\
\hline \multicolumn{7}{|l|}{ Group 1} \\
\hline$(\mathrm{AGG}) 7 /(\mathrm{AGG}) 7$ & 47.8 & 44.6 & 45.9 & 47.8 & 49.6 & 40.0 \\
\hline$(A G G) 7 /(A G G) n o n$ & 43.9 & 45.4 & 41.4 & 41.0 & 46.2 & 51.8 \\
\hline (AGG)non/(AGG)non & 8.3 & 10.0 & 12.6 & 11.2 & 4.2 & 8.2 \\
\hline P-value & \multicolumn{2}{|c|}{0.40} & \multicolumn{2}{|c|}{0.69} & \multicolumn{2}{|r|}{0.09} \\
\hline \multicolumn{7}{|l|}{ Group 2} \\
\hline$(\mathrm{AGG}) 5 /(\mathrm{AGG}) 6$ & 0.4 & - & 0.9 & - & - & - \\
\hline$(\mathrm{AGG}) 5 /(\mathrm{AGG}) 7$ & 5.7 & 1.8 & 5.4 & 2.5 & 5.9 & 0.9 \\
\hline$(\mathrm{AGG}) 6 /(\mathrm{AGG}) 6$ & 7.8 & 10.0 & 11.7 & 11.2 & 4.2 & 8.2 \\
\hline$(\mathrm{AGG}) 6 /(\mathrm{AGG}) 7$ & 37.0 & 43.5 & 35.1 & 38.5 & 38.7 & 50.9 \\
\hline$(\mathrm{AGG}) 7 /(\mathrm{AGG}) 7$ & 47.8 & 44.6 & 45.9 & 47.8 & 49.6 & 40.0 \\
\hline (AGG)7/(AGG)8 & 0.9 & - & 0.9 & - & 0.8 & - \\
\hline$(\mathrm{AGG}) 7 /(\mathrm{AGG}) 9$ & 0.4 & - & - & - & 0.8 & - \\
\hline P-value & \multicolumn{2}{|c|}{0.30} & \multicolumn{2}{|c|}{0.98} & \multicolumn{2}{|r|}{0.10} \\
\hline
\end{tabular}

'The wild-type genotype is the 'non-del' genotype which signifies there is no 2-base pair deletion present. The term ' 2 bp-del' signifies the polymorphic genotype with the 2 -base pair deletion. ${ }^{\text {b }}$ The (AGG) 7 is considered the wild-type genotype.

polymorphic genotype in the study population showed the wild-type genotype (non-del/non-del) present in $>60 \%$ of the subjects, with the heterozygous genotype (non-del/2 bp-del) present in $\sim 30 \%$ of subjects, and the doubly polymorphic genotype ( $2 \mathrm{bp}-\mathrm{del} / 2 \mathrm{bp}-\mathrm{del})$ present in $<10 \%$ of the subjects. A modest trend was evident with the $2 \mathrm{bp}-\mathrm{del} / 2 \mathrm{bp}-\mathrm{del}$ genotype being more prevalent in the cases $(7.7 \%)$ than in the controls (5.1\%); however, these differences were not statistically significant. This modest trend was also observed in the premenopausal cases and controls (6.6 vs. $4.2 \%$, respectively) as well as in the postmenopausal cases and controls (8.6 vs. $6.5 \%$, respectively).

When assessing the IGF-1R (AGG)n repeat polymorphism, the distribution of the (AGG)n alleles was $\sim 45 \%$ for the wildtype genotype (AGG)7/(AGG)7, 45\% for the heterozygous repeat genotype (AGG)7/(AGG)non, and $\sim 10 \%$ for the polymorphic genotype (AGG)non/(AGG)non. The specific (AGG) non genotype noted with a higher frequency in the cases was the (AGG) 5 repeat with $\sim 3.0 \%$ of cases having this genotype compared to $\sim 1.0 \%$ of the controls. Furthermore, the $>(\mathrm{AGG}) 7$ alleles, (AGG) 8 and (AGG) 9 were only noted in the cases. The (AGG)6 genotype was more prevalent in the controls than in the cases, with the distribution difference at its greatest (by $10 \%$ ) in the postmenopausal women (23.6 in cases vs. $33.6 \%$ in controls). When stratifying the genotype distribution by (AGG)7 vs. (AGG)non, the (AGG)non/(AGG)non genotype was overall present at a greater frequency in the controls than in the cases. In the postmenopausal women $8.2 \%$ of the controls had the (AGG)non genotype compared to $4.2 \%$ of the cases, although the difference was not statistically significant $(\mathrm{P}=0.09)$.

Odds ratios and $95 \%$ confidence intervals for the IGF-1, $I G F B P-3, I G F-1 R$ genotypes with breast cancer. The results of the univariate and multivariate analyses of the association between IGF polymorphisms and breast cancer are shown 
Table V. Odds ratios and 95\% confidence intervals for the IGF-1, IGFBP-3, IGF-1R genotypes with breast cancer.

\begin{tabular}{|c|c|c|c|c|}
\hline & \multicolumn{2}{|c|}{ Univariate } & \multicolumn{2}{|c|}{ Multivariate $^{\mathrm{a}}$} \\
\hline & OR $(95 \% \mathrm{CI})$ & P-value & OR $(95 \% \mathrm{CI})$ & P-value \\
\hline \multicolumn{5}{|l|}{ IGF-1 (CA)n genotype } \\
\hline \multicolumn{5}{|l|}{ Group 1} \\
\hline $19 / 19$ & 1.00 (ref) & - & 1.00 (ref) & - \\
\hline 19/non-19 & $0.94(0.61-1.45)$ & 0.774 & $1.10(0.63-1.93)$ & 0.739 \\
\hline Non-19/non-19 & $1.75(1.07-2.88)$ & 0.027 & $1.98(1.01-3.89)$ & 0.047 \\
\hline \multicolumn{5}{|l|}{ Group 2} \\
\hline$<(\mathrm{CA}) 19$ & $1.70(1.19-2.43)$ & 0.003 & $1.97(1.21-3.22)$ & 0.006 \\
\hline$=(\mathrm{CA}) 19$ & 1.00 (ref) & - & 1.00 (ref) & - \\
\hline$>(\mathrm{CA}) 19$ & $1.16(0.87-1.56)$ & 0.319 & $1.16(0.79-1.70)$ & 0.449 \\
\hline \multicolumn{5}{|l|}{ Group 3} \\
\hline 19 allele present & 1.00 (ref) & - & 1.00 (ref) & - \\
\hline 19 allele absent & $1.82(1.20-2.77)$ & 0.005 & $1.87(1.05-3.32)$ & 0.005 \\
\hline \multicolumn{5}{|l|}{ IGFBP-3 genotype } \\
\hline AA & 1.00 (ref) & - & 1.00 (ref) & - \\
\hline $\mathrm{AC}$ & $0.73(0.41-1.29)$ & 0.275 & $0.59(0.27-1.27)$ & 0.177 \\
\hline $\mathrm{CC}$ & $0.68(0.39-1.20)$ & 0.182 & $0.73(0.34-1.55)$ & 0.409 \\
\hline \multicolumn{5}{|l|}{ IGF-IR 2 bp deletion } \\
\hline Non-del/non-del & 1.00 (ref) & - & 1.00 (ref) & - \\
\hline Non-del/ 2 bp-del & $0.90(0.62-1.30)$ & 0.560 & $1.04(0.59-1.83)$ & 0.902 \\
\hline 2 bp-del/2 bp-del & $1.57(0.78-3.16)$ & 0.212 & $1.16(0.39-3.48)$ & 0.796 \\
\hline \multicolumn{5}{|l|}{ IGF-IR (AGG)n } \\
\hline$(\mathrm{AGG}) 5$ & 3.18 (1.31-8.94) & 0.028 & $2.22(0.43-11.4)$ & 0.338 \\
\hline (AGG)6 & $0.81(0.61-1.06)$ & 0.434 & $0.93(0.62-1.38)$ & 0.703 \\
\hline$(\mathrm{AGG}) 7$ & 1.00 (ref) & - & 1.00 (ref) & - \\
\hline$(\mathrm{AGG}) 8^{\mathrm{b}}$ & - & - & - & - \\
\hline$(\mathrm{AGG}) 9^{\mathrm{b}}$ & - & - & - & - \\
\hline \multicolumn{5}{|l|}{ Group 1} \\
\hline$(\mathrm{AGG}) 7 /(\mathrm{AGG}) 7$ & 1.00 (ref) & - & 1.00 (ref) & - \\
\hline$(\mathrm{AGG}) 7 /(\mathrm{AGG})$ non & $0.90(0.63-1.31)$ & 0.589 & $0.94(0.54-1.64)$ & 0.831 \\
\hline (AGG)non/(AGG)non & $0.77(0.41-1.47)$ & 0.434 & $1.05(0.46-2.43)$ & 0.905 \\
\hline \multicolumn{5}{|l|}{ Group 2} \\
\hline$(\mathrm{AGG}) 5 /(\mathrm{AGG}) 6^{\mathrm{b}}$ & - & - & - & - \\
\hline$(\mathrm{AGG}) 5 /(\mathrm{AGG}) 7$ & $2.86(0.99-8.28)$ & 0.053 & $1.33(0.29-6.07)$ & 0.716 \\
\hline$(\mathrm{AGG}) 6 /(\mathrm{AGG}) 6$ & $0.77(0.38-1.41)$ & 0.350 & $0.99(0.43-2.31)$ & 0.984 \\
\hline$(\mathrm{AGG}) 6 /(\mathrm{AGG}) 7$ & $0.79(0.54-1.16)$ & 0.230 & $0.86(0.49-1.52)$ & 0.600 \\
\hline$(\mathrm{AGG}) 7 /(\mathrm{AGG}) 7$ & 1.00 (ref) & - & 1.00 (ref) & - \\
\hline$(\mathrm{AGG}) 7 /(\mathrm{AGG}) 8^{\mathrm{b}}$ & - & - & - & - \\
\hline$(\mathrm{AGG}) 7 /(\mathrm{AGG}) 9^{\mathrm{b}}$ & - & - & - & - \\
\hline
\end{tabular}

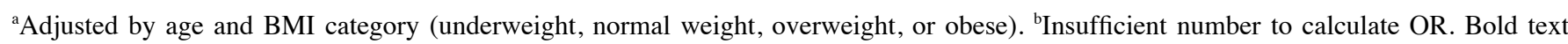
denotes statistically significant values.

in Table V. For the IGF-1 (CA)n repeat, there was a significant association of the non-19/non-19 genotype with breast cancer by univariate analysis $(\mathrm{OR}=1.75 ; 95 \% \mathrm{CI}=1.07-2.88$; $\mathrm{P}=0.027$ ). When adjusting for age and $\mathrm{BMI}$, there was still a statistically significant association of breast cancer with the non-19/non-19 genotype $(\mathrm{OR}=1.98 ; 95 \% \mathrm{CI}=1.01-3.89$;
$\mathrm{P}=0.047)$. Considering the association of single alleles with breast cancer, the $<(\mathrm{CA}) 19$ allele was significantly associated with breast cancer both in the univariate analysis $(\mathrm{OR}=1.70$; 95\% $\mathrm{CI}=1.19-2.43 ; \mathrm{P}=0.003)$ and the multivariate analysis $(\mathrm{OR}=1.97 ; 95 \% \mathrm{CI}=1.21-3.22 ; \mathrm{P}=0.006)$. Furthermore, the 'absence of the 19 allele' was strongly associated with breast 
cancer in both univariate $(\mathrm{OR}=1.82 ; 95 \%$ CI 1.20-2.77; $\mathrm{P}=0.005)$ and multivariate analyses $(\mathrm{OR}=1.87 ; 95 \% \mathrm{CI}=1.05$ 3.32; $\mathrm{P}=0.005)$. The IGFBP-3 polymorphisms showed no significant association with breast cancer. The IGF-1R 2-bp deletion polymorphism analysis did not reveal any significant association with breast cancer. The IGF-1R (AGG)n repeat analysis did show some significant association of the polymorphic genotypes with breast cancer. In the univariate analysis, the (AGG)5 genotype was significantly associated with breast cancer $(\mathrm{OR}=3.18 ; 95 \% \mathrm{CI}=1.31-8.94 ; \mathrm{P}=0.028)$. However, when the analysis was adjusted for age and BMI, the significance was lost $(\mathrm{OR}=1.64 ; 95 \% \mathrm{CI}=0.39-6.89 ; \mathrm{P}=0.501)$. The rarity of the allele in the study population may account for this finding or it may be due to the influence of age and/or $\mathrm{BMI}$ on the affects from this allele. When discretely grouping the (AGG)n polymorphism by wild-type (AGG)7 vs. (AGG) non, there were no statistically significant associations. However, when considering the distribution of the various allele combinations, the (AGG)5/(AGG)7 allele was bordering statistical significance by univariate analysis $(\mathrm{OR}=2.86 ; 95 \%$ $\mathrm{CI}=0.99-8.28 ; \mathrm{P}=0.053)$. This associated observation was once again lost when adjusting for age and $\mathrm{BMI}$ in the multivariate analysis $(\mathrm{OR}=1.33 ; 95 \% \mathrm{CI}$ 0.29-6.07; $\mathrm{P}=0.716)$.

Odds ratios and 95\% confidence intervals for the IGF-1, IGFBP-3, IGF-1R polymorphic genotypes with clinicopathological features. The clinicopathological details from breast cancer patients were available for approximately 200 patients out of 268 total cancer patients in this study. There were no significant associations between IGF polymorphisms and tumor characteristics and receptor subtypes (data not shown).

\section{Discussion}

Our current study provides additional support for the association between IGF-1 polymorphic genotypes and breast cancer. Our findings show that breast cancer patients, particularly premenopausal women, were more likely to be carriers of the non-19 (CA)n alleles, and these alleles were more likely to be the $<(\mathrm{CA}) 19$ genotype. The association of the $<(\mathrm{CA}) 19$ genotype with breast cancer found in our study as well as data from a much larger case-control study (31), imply that the length of polymorphic repeats could inversely affect transcription. There was no association found with $>$ (CA)19 repeats with a decreased risk of cancer; suggesting that the possible transcriptional effects resulting from the length of the polymorphism may be limited to the $<(\mathrm{CA}) 19$ repeats.

Breast cancer patients were also more likely to have the non-19/non-19 genotype when compared to women with no breast cancer. This finding was most significant in premenopausal breast cancer patients. We previously published the findings of a significant association of increased IGF-1 serum levels in minority premenopausal women with breast cancer, decreased response to treatment, poor prognosis and outcome (6). The findings in the present study, which includes the same study population, found a significant association of the IGF-1 polymorphism with breast cancer, especially in premenopausal but not postmenopausal women. Consequently, these results suggest, to a modest extent, a potential role that IGF-1 levels and promoter polymorphisms may play in breast cancer in premenopausal women. The role of IGF-1 in premenopausal women with breast cancer is further supported by the findings of other investigations $(20,31,38-41)$.

One of the most convincing studies that demonstrate a direct link between the IGF-1 (CA)n repeat and risk for breast cancer was the Long Island Breast Cancer Study Project by Cleveland et al (31). These investigators examined 1028 breast cancer cases and 1086 controls. They observed an increased risk of breast cancer for genotypes that included alleles with fewer than (CA)19 repeats when compared to (CA)19 repeat carriers. This association was stronger among premenopausal women. No significant association was observed between an IGF-1 genotype with no (CA)19 repeat compared to (CA)19 repeat genotypes in either pre- or postmenopausal women. However, when traditional breast cancer risk factors were considered, premenopausal women with genotypes that lacked a (CA)19 repeat had a nearly $60 \%$ increased risk of breast cancer among those who had ever used hormonal birth control, while never users had a significantly reduced risk. Among postmenopausal women, those with genotypes lacking a (CA)19 repeat allele had significantly increased breast cancer risk among subjects with a lower than median body mass index (BMI), while no association of the IGF-1 genotype was noted among women with a higher than median BMI.

Several other groups have suggested that polymorphisms of the IGF-1 gene and of genes encoding for the major IGF-1 carriers may predict circulating levels of IGF-1 and have an impact on cancer risk. Canzian et al (19) tested this hypothesis with a case-control study of 807 breast cancer patients and 1588 matched control subjects, nested within the European Prospective Investigation into Cancer and Nutrition (EPIC). The authors found a weak but significant association of polymorphisms at the 5' end of the IGF-1 gene with breast cancer risk, particularly among women younger than 55 years, and a strong association of polymorphisms located in the $5^{\prime}$ end of IGFBP-3 with circulating levels of IGFBP-3. Although, we observed a direct correlation with breast cancer risk in premenopausal African-American and Hispanic women with an increase in IGF-1 plasma levels, together with a decrease in serum IGFBP-3 levels (6), we did not determine these associations with their IGF gene polymorphic status.

Cheng et al (42) examined a large multiethnic cohort for an association between IGFBP-1 and IGFBP-3 genotypes with either prostate or breast cancer risk. However, unlike our current study, their breast cancer cohort was primarily postmenopausal. Their data did not observe a strong association between IGFBP-1 and IGFBP-3 genotypes with either prostate or breast cancer risk. The number of African Americans and Latinos in their study included cases/controls as follows: AA 284/418 and Latinos 330/380. Although the present study had fewer subjects, our data also confirmed no association between the IGFBP-3 polymorphism (A-202C) with breast cancer in either population. Other investigators reported similar findings primarily for Caucasian women (19). Al-Zahrani et al (43) observed similar risks for breast cancer between premenopausal and postmenopausal women with either IGF-1 or IGFBP-3 SNPs.

However, it is necessary to note that a limitation of our study was a smaller sample size ( 500 women) than the aforementioned studies, and this may play a role in assessing the 
associations of this genotype with breast cancer. Nonetheless, the suggested importance of this genotype playing a role in premenopausal women, particularly perhaps minority women, does merit some consideration. These data, however, must be interpreted noting that this was a hospital-based comparison study, where there was a trend in difference in age distribution between cases and controls. Although a comparison study is a limitation, the fact that there is an association of the IGF-1 genotype with cancer in younger women, while cancer is predominately considered a later-age malady, does somewhat support the strength of the relevance of these findings.

To date, there have been only a few studies which have evaluated the distribution of the IGF-1 (CA)n alleles in African-American and Hispanic/Latino women with breast cancer (36,41-46). Slattery and colleagues (45) reported that non-Hispanic white (NHW) women in the Southwestern US, who were not recently exposed to hormones, and did not have the $19 \mathrm{CA}$ repeat of the IGF-1 gene, showed an association with breast cancer. The R allele of G972R of the IRS polymorphism was less common in Hispanic women and was associated with breast cancer risk in women not recently exposed to hormones. These authors demonstrated several interesting additional associations. For instance, among postmenopausal Hispanic women recently exposed to hormones, the A allele of the $-202 \mathrm{C}>\mathrm{A}$ IGFBP3 polymorphism increased the risk of breast cancer. The IGF-1 $19 \mathrm{CA}$ repeat polymorphism interacted with hormone replacement therapy (HRT) among NHW postmenopausal women. Women who carried the 19/19 IGF-1 genotype had a reduced risk of breast cancer when they did not use HRT. Their study also demonstrated an association between body mass index (BMI) and IGF-1 $19 \mathrm{CA}$ repeat $(\mathrm{P}=0.06)$ and between weight gain and the $-202 \mathrm{C}>\mathrm{A}$ IGFBP-3 polymorphism $(\mathrm{P}=0.05)$ in NHW postmenopausal women not recently exposed to hormones. In the present study, due to limited sample size, we were not able to examine with statistical significance, the breast cancer risks associated with BMI and the use of HRT in either the IGF-1 and/or IGFBP-3 genotypes. However, these are important risk factors and warrant further studies in African-American and Hispanic women.

Similar to our study which includes a suitable number of African-American women, other studies assessing IGF-1 genotype and IGF-1 levels found that African-American women were more likely to be carriers of the non-19 allele, particularly the $<(\mathrm{CA}) 19$ alleles, when compared to mostly non-Hispanic Caucasian women $(36,41)$. Furthermore, our study supports previous findings that the most common IGF-1 genotype is the heterozygous 19/non-19 IGF-1 genotype $(36,41)$. An important study to consider was one performed by DeLellis et al (36). This study included African-American and Hispanic/Latino subjects from Los Angeles, Southern California. The authors found that the non-19/non-19 genotype was more prevalent in AfricanAmerican women compared to Hispanic/Latino women. In addition, the distribution of the IGF-1 alleles between the two ethnic groups showed a pattern similar to ours, with the highest prevalence once again being the heterozygous genotype, followed by the homozygous wild-type genotype, and finally the homozygous non-wild-type genotype (36). The distribution of the IGFBP-3 genotype in our study was similar to other studies that had included Hispanic/ Latino women $(45,46)$. There was a greater prevalence of the heterozygous $\mathrm{AC}$ and the homozygous $\mathrm{CC}$ genotypes than the homozygous wild-type genotype AA. Here, it should be noted that in our study, pooling both African-American and Hispanic/Latino women into one 'total subjects' category was carried out in order to gain an understanding of the distribution of IGF gene polymorphisms and to have a suitable number of women to perform meaningful statistical analyses. A possible limitation of the present study may be that the subjects were not matched by ethnicity, and there were more Hispanic/Latino women represented than African-Americans in this clinic-based comparison study.

Perhaps the strongest association between IGF-1 CA repeats and risk for colorectal cancer cases is found in the hereditary form of CRC $(47,48)$. Zecevic et al $(47)$ investigated the relationship between IGF-1 promoter cytosine-adenine (CA) dinucleotide-repeat polymorphism length and CRC risk in 121 MMR gene mutation carriers using Cox regression and Kaplan-Meier analysis. This study was primarily carried out in Caucasian patients. Their data demonstrated a statistically significant association between shorter IGF-1 CA-repeat lengths and increased risk for CRC in hereditary non-polyposis colon cancer (HNPCC) carriers. Similar observations were made recently by Reeves et al (48), who examined both Australian and Polish patients with MMR gene mutations (equally in MLH1 or MSH2). The authors concluded that the IGF-1 CA repeat is an important modifier of disease onset in HNPCC and the first polymorphism to yield consistent results across different populations.

In a study of prostate cancer patients of African-American ethnicity, Hernandez et al (44) showed that the two polymorphisms, rs7965399 C/T SNP and IGF-1 (CA)n repeat, do not affect IGF-1 serum levels nor prostate cancer risk. In addition, these authors showed that, although the IGFBP-3 serum levels are not associated with prostate cancer risk, the $\mathrm{C}$ allele of the 202 A/C SNP increases risk and lowers IGFBP-3 serum levels. The authors caution that the impact of these genotypes may not be significant, given the high rates of aggressive disease in their prostate cancer population. This possibility was recently examined by Hoyo et al (49) in albeit a small population of African Americans and whites from the Durham Veterans Administration Hospital. Essentially, they grouped 47 cases with Gleason sum $>7$, and 50 cases with Gleason sum $<7$ and compared them to 93 controls. Their data confirmed that the inverse association between carrying the IGF-1 (CA)19 repeat variant did not vary with grade or ethnicity. However, the association between the IGFBP-3 C allele and prostate cancer was grade-specific in both ethnic groups.

Recent studies on non-small cell lung (50), ovarian (51) and pancreatic cancer (52) provide further support for studying IGF family member SNPs as predictors for cancer risk and prognosis (49). In the case of pancreatic cancer, Suzuki et al (52) found that the IGF-1 -177 GC/CC genotype was related to lower frequency of diabetes in the controls and higher frequency of diabetes in cases among the genotype carriers. We plan to examine this SNP variant in our patient population.

The two IGF-1R polymorphisms assessed in our study population have only been examined in the context of cancer 
by only one other study (25). The authors examined the influence of IGF-1R polymorphisms on IGF-1 levels and prostate cancer risk. The study found that having a polymorphic genotype composed of fewer than two copies of the (AGG)7 polymorphisms [i.e. non(AGG)7/(AGG)7 or non(AGG)7/ non(AGG)7] was associated with an increased risk of prostate cancer, and interestingly, lower levels of IGF-1. The association with lower IGF-1 levels and increased prostate risk found in the study is an unexpected finding since increased IGF-1 levels have been associated with an increased risk of multiple cancers in large meta-analysis studies (40). We identified a modest trend towards the significance of the (AGG)5 genotype and (AGG)5/(AGG)7 genotype with an increased OR with breast cancer. The association with the $<(\mathrm{AGG}) 7$ repeats in the aforementioned prostate study and our finding of the (AGG) 5 repeat association with breast cancer both link this IGF-1R polymorphic genotype with cancer. In our study, however, upon adjusting for age and BMI, the significance of this association was lost. These results warrant careful interpretation since this allele was found at a low frequency in our study cohort and may present a chance finding. Furthermore, the functional relevance of this polymorphism is still unclear; therefore, understanding the contribution of the polymorphism to gene expression and ultimately cancer is required before this polymorphism may be useful as a risk-associated biomarker.

In conclusion, our study confirms that the IGF-1 (CA) repeat is associated with breast cancer, and this polymorphism may play a functional role in the transcription of IGF-1 and influence plasma or circulating IGF-1 levels. This study provides further support for a link between IGF-1 serum levels (6) and breast cancer in premenopausal minority women, and that this cohort of minority women is more likely to express non-19/non-19 IGF-1 genotypes. Additionally, our study found a significant association of the IGF-1R (AGG)5 polymorphic genotype and breast cancer. These findings modestly suggest that polymorphisms in the IGF axis (ranging from the ligand to receptor) may be potentially important cancer risk-association biomarkers. Additional studies should analyze combined polymorphic panels along the IGF pathway which will assess whether combinations of risk-associated IGF polymorphisms may reveal stronger predictive associations with cancer.

Further consideration of ethnic-specific differences, if any, requires additional investigation and an increase in the number of women studied. More studies are necessary to elucidate the underlying mechanisms which can explain the associations found between IGF gene polymorphisms and breast cancer.

\section{Acknowledgements}

We would like to thank all of the amazing women who are participating in the ongoing breast cancer studies conducted by the Division of Cancer Research and Training at Charles Drew University. We could not have accomplished this research without their generous cooperation. This study was supported, in part, by grants from the NIH/National Cancer Institute U54CA14393; U56 CA101599; CA15083-25S3; R25DK067015-01; and Department of Defense Breast Cancer Research Program grant BC043180 to J.V.V.

\section{References}

1. LeRoith D and Raizada MK (eds): Proceedings of the 4th International Symposium on Insulin, IGFs, and their Receptors. Adv Exp Med Biol 343: 1-417, 1993.

2. Jones JI and Clemmons DR: Insulin-like growth factors and their binding proteins: biological actions. Endocr Rev 16: 3-34, 1995.

3. Macaulay VM: Insulin-like growth factors and cancer. Br J Cancer 65: 311-320, 1992.

4. Karey KP and Sirbasku DA: Differential responsiveness of human breast cancer cell lines MCF-7 and T47D to growth factors and 17 beta-estradiol. Cancer Res 48: 4083-4092, 1988.

5. Pollak M, Costantino J, Polychronakos C, et al: Effect of tamoxifen on serum insulin-like growth factor I levels in stage I breast cancer patients. J Natl Cancer Inst 82: 1693-1697, 1990.

6. Vadgama JV, Wu Y, Datta G, Khan H and Chillar R: Plasma insulin-like growth factor-I and serum IGF-binding protein 3 can be associated with the progression of breast cancer, and predict the risk of recurrence and the probability of survival in African American and Hispanic women. Oncology 57: 330-340, 1999.

7. Hankinson SE, Willett WC, Colditz GA, et al: Circulating concentrations of insulin-like growth factor-I and risk of breast cancer. Lancet 351: 1393-1396, 1998.

8. Rinaldi S, Peeters PHM, Berrino F, et al: IGF-1, IGFBP-3 and breast cancer risk in women: The European Prospective Investigation into Cancer and Nutrition (EPIC). Endocr Relat Cancer 13: 593-605, 2006.

9. Baglietto L, English DR, Hopper JL, Morris HA, Tilley WD and Giles GG: Circulating insulin-like growth factor-I and binding protein-3 and the risk of breast cancer. Cancer Epidemiol Biomarkers Prev 16: 763-768, 2007.

10. Toniolo P, Bruning PF, Akhmedkhanov A, et al: Serum insulinlike growth factor-I and breast cancer. Int J Cancer 88: 828-832, 2000.

11. Byrne C, Colditz GA, Willett WC, Speizer FE, Pollak M and Hankinson SE: Plasma insulin-like growth factor (IGF) I, IGF-binding protein 3, and mammographic density. Cancer Res 60: 3744-3748, 2000.

12. Boyd NF, Stone J, Martin LJ, et al: The association of breast mitogens with mammographic densities. Br J Cancer 87: 876-882, 2002.

13. Maskarinec G, Williams AE and Kaaks R: A cross-sectional investigation of breast density and insulin-like growth factor I. Int J Cancer 107: 991-996, 2003.

14. Harrela M, Koistinen H, Kaprio J, et al: Genetic and environmental components of interindividual variation in circulating levels of IGF-1, IGF-1I, IGFBP-1, and IGFBP-3. J Clin Invest 98: 2612-2615, 1996.

15. Rosen CJ, Kurland ES, Vereault D, et al: Association between serum insulin growth factor-I (IGF-1) and a simple sequence repeat in IGF-1 gene: implications for genetic studies of bone mineral density. J Clin Endocrinol Metab 83: 2286-2290, 1998.

16. Li YC, Korol AB, Fahima T and Nevo E: Microsatellites within genes: structure, function, and evolution. Mol Biol Evol 21: 991-1007, 2004.

17. Yu H, Li BD, Smith M, Shi R, Berkel HJ and Kato I: Polymorphic CA repeats in the IGF-1 gene and breast cancer. Breast Cancer Res Treat 70: 117-122, 2001.

18. Chen X, Guan J, Song Y, et al: IGF-1 (CA) repeat polymorphisms and risk of cancer: a meta-analysis. J Hum Genet 53: 227-238, 2008.

19. Canzian F, McKay JD, Cleveland RJ, et al: Polymorphisms of genes coding for insulin-like growth factor 1 and its major binding proteins, circulating levels of IGF-1 and IGFBP-3 and breast cancer risk: results from the EPIC study. Br J Cancer 94: 299-307, 2006.

20. Jernstrom H, Deal C, Wilkin F, et al: Genetic and non-genetic factors associated with variation of plasma levels of insulin-like growth factor-I and insulin-like growth factor-binding protein-3 in healthy premenopausal women. Cancer Epidemiol Biomarkers Prev 10: 377-384, 2001.

21. Larsson O, Girnita A and Girnita L: Role of insulin-like growth factor 1 receptor signaling in cancer. Br J Cancer 92: 2097-2101, 2005.

22. LeRoith D and Roberts CT Jr: The insulin-like growth factor system and cancer. Cancer Lett 195: 127-137, 2003. 
23. Almeida A, Muleris M, Dutrillaux B and Malfoy B: The insulinlike growth factor I receptor gene is the target for the $15 \mathrm{q} 26$ amplicon in breast cancer. Genes Chromosomes Cancer 11: $63-65,1994$

24. Xie Y, Skytting B, Nilsson G, Brodin B and Larsson O: Expression of insulin-like growth factor-1 receptor in synovial sarcoma: association with an aggressive phenotype. Cancer Res 59: 3588-3591, 1999.

25. Chen C, Freeman R, Voigt LF, Fitzpatrick A, Plymate SR and Weiss NS: Prostate cancer risk in relation to selected genetic polymorphisms in insulin-like growth factor-I, insulin-like growth factor binding protein-3, and insulin-like growth factor-I receptor. Cancer Epidemiol Biomarkers Prev 15: 2461-2466, 2006.

26. Figer A, Karasik YP, Baruch RG, et al: Insulin-like growth factor I polymorphism and breast cancer risk in Jewish women. Isr Med Assoc J 4: 759-762, 2002.

27. Yu H, Jin F, Shu XO, et al: Insulin-like growth factors and breast cancer risk in Chinese women. Cancer Epidemiol Biomarkers Prev 11: 705-712, 2002.

28. Morimoto LM, Newcomb PA, White E, Bigler J and Potter JD: Variation in plasma insulin-like growth factor-1 and insulinlike growth factor binding protein-3: genetic factors. Cancer Epidemiol Biomarkers Prev 14: 1394-1401, 2005.

29. Wagner K, Hemminki K, Israelsson E, et al: Polymorphisms in the IGF-1 and IGFBP-3 promoter and the risk of breast cancer. Breast Cancer Res Treat 92: 133-140, 2005.

30. Wen W, Gao YT, Shu XO, et al: Insulin-like growth factor-I gene polymorphism and breast cancer risk in Chinese women. Int J Cancer 113: 307-311, 2005.

31. Cleveland RJ, Gammon MD, Edmiston SN, et al: IGF-1 CA repeat polymorphisms, lifestyle factors and breast cancer risk in the Long Island Breast Cancer Study Project. Carcinogenesis 27: 758-765, 2006

32. Bågeman $\mathrm{E}$, Ingvar $\mathrm{C}$, Rose $\mathrm{C}$ and Jernström $\mathrm{H}$ : Absence of the common insulin-like growth factor-1 19-repeat allele is associated with early age at breast cancer diagnosis in multiparous women. Br J Cancer 96: 712-717, 2007.

33. Patel AV, Cheng I, Canzian F, et al: IGF-1, IGFBP-1, and IGFBP-3 polymorphisms predict circulating IGF levels but not breast cancer risk: findings from the Breast and Prostate Cancer Cohort Consortium (BPC3). PLoS One 3: e2578, 2008.

34. Missmer SA, Haiman CA, Hunter DJ, et al: A sequence repeat in the insulin-like growth factor-1 gene and risk of breast cancer. Int J Cancer 100: 332-336, 2002.

35. Kato J, Eastham B, Li M, Smith and Yu H: Genotype-phenotype analysis for the polymorphic CA repeat in the insulin-like growth factor-I (IGF-1) gene. Eur J Epidemiol 18: 203-209, 2003.

36. DeLellis $\mathrm{K}$, Ingles $\mathrm{S}$, Kolonel L, et al: IGF-1 genotype, mean plasma level and breast cancer risk in the Hawaii/Los Angeles multiethnic cohort. Br J Cancer 88: 277-282, 2003.

37. González-Zuloeta Ladd AM, Liu F, Houben MP, et al: IGF-1 CA repeat variant and breast cancer risk in postmenopausal women. Eur J Cancer 43: 1718-1722, 2007.

38. Fehringer G, Ozcelik H, Knight JA, Paterson AD and Boyd NF: Association between IGF1 CA microsatellites and mammographic density, anthropometric measures, and circulating IGF-I levels in premenopausal Caucasian women. Breast Cancer Res Treat 116: 413-423, 2009
39. Fehringer G, Boyd NF, Knight JA, et al: Family-based genetic association study of insulin-like growth factor I microsatellite markers and premenopausal breast cancer risk. Breast Cancer Res Treat 118: 415-424, 2009.

40. Renehan AG, Zwahlen M, Minder C, O'Dwyer ST, Shalet SM and Egger M: Insulin-like growth factor (IGF)-I, IGF binding protein-3, and cancer risk: systematic review and metaregression analysis. Lancet 63: 1346-1353, 2004.

41. Jernström $\mathrm{H}, \mathrm{Chu} \mathrm{W}$, Vesprini $\mathrm{D}$, et al: Genetic factors related to racial variation in plasma levels of insulin-like growth factor-1: implications for premenopausal breast cancer risk. Mol Genet Metab 72: 144-154, 2001.

42. Cheng I, Penney KL, Stram DO, et al: Haplotype-based association studies of IGFBP1 and IGFBP3 with prostate and breast cancer risk: the multiethnic cohort. Cancer Epidemiol Biomarkers Prev 15: 1993-1997, 2006.

43. Al-Zahrani A, Sandhu MS, Luben RN, et al: IGF-1 and IGFBP3 tagging polymorphisms are associated with circulating levels of IGF-1, IGFBP3 and risk of breast cancer. Hum Mol Genet 15: $1-10,2006$.

44. Hernandez W, Grenade C, Santos ER, Bonilla C, Ahaghotu C and Kittles RA: IGF-1 and IGFBP-3 gene variants influence on serum levels and prostate cancer risk in African Americans. Carcinogenesis 28: 2154-2459, 2007.

45. Slattery ML, Sweeney C, Wolff R, et al: Genetic variation in IGF-1, IGFBP3, IRS1, IRS2 and risk of breast cancer in women living in Southwestern United States. Breast Cancer Res Treat 104: 197-209, 2007.

46. Sweeney C, Murtaugh MA, Baumgartner KB, et al: Insulin-like growth factor pathway polymorphisms associated with body size in Hispanic and non-Hispanic white women. Cancer Epidemiol Biomarkers Prev 14: 1802-1809, 2005.

47. Zecevic M, Amos CI, Gu X, et al: IGF-1 gene polymorphism and risk for hereditary non-polyposis colorectal cancer. J Natl Cancer Inst 98: 139-143, 2006.

48. Reeves SG, Rich D, Meldrum CJ, et al: IGF-1 is a modifier of disease risk in hereditary non-polyposis colorectal cancer. Int J Cancer 123: 1339-1343, 2008 .

49. Hoyo C, Grubber J, Demark-Wahnefried W, et al: Grade-specific prostate cancer associations of IGF-1 (CA) 19 repeats and IGFBP3-202A/C in blacks and whites. J Natl Med Assoc 99: 718-722, 2007.

50. Zhang M, Hu Z, Huang J, et al: A 3'-untranslated region polymorphism in IGF-1 predicts survival of non-small cell lung cancer in a Chinese population. Clin Cancer Res 6: 1236-1244, 2010.

51. Terry K, Tworoger SS, Gates MA, et al: Common genetic variant in IGF-1, IGFBP1 and IGFBP3 and ovarian cancer. Carcinogenesis 30: 2042-2046, 2009.

52. Suzuki H, Li Y, Dong X, Hassan MM, et al: Effect of insulinlike growth factor gene polymorphisms alone or in interaction with diabetes on the risk of pancreatic cancer. Cancer Epidemiol Biomarkers Prev 17: 3467-3473, 2008. 